OPEN ACCESS

Edited by:

Kuo-Lun Hsiao,

National Taichung University of Science and Technology, Taiwan

Reviewed by:

Mostafa Janebi Enayat,

University of Maragheh, Iran

Chun Chia Lee,

Minnan Normal University, China

${ }^{*}$ Correspondence:

Tan Jiang

Jiangtan@scnu.edu.cn

Specialty section: This article was submitted to Educational Psychology, a section of the journal

Frontiers in Education

Received: 12 August 2021

Accepted: 14 January 2022

Published: 11 February 2022

Citation:

Li P, Fang $Z$ and Jiang T (2022) Research Into improved Distance Learning Using VR Technology. Front. Educ. 7:757874. doi: 10.3389/feduc.2022.757874

\section{Research Into improved Distance Learning Using VR Technology}

\author{
Pengfei $\mathrm{Li}^{1}$, Zelong Fang ${ }^{2}$ and Tan Jiang ${ }^{3 *}$ \\ ${ }^{1}$ Art College of Jinan University, Guangzhou, China, ${ }^{2}$ Guangzhou Nidu Information Technology Co., Ltd., Guangzhou, China, \\ ${ }^{3}$ School of Fine Art, South China Normal University, Guangzhou, China
}

Practical skill-based education requires exemplary face-to-face operational teaching, and VR can enhance online distance learning, facilitating an alternative form of "face-to-face" teaching, which results in better teacher-student communication and learner self-efficacy. It also constitutes as a useful substitute for in-person teaching, and it also has a positive impact on learning effectiveness. In this study, a mixed-method approach was used, which utilized the following methodologies: a combination of quantitative and qualitative measures, document collection, case and comparative analysis, and VR teaching that utilizes "You, Calligrapher" as a survey tool. Teachers and students of art were selected, who then used an educational VR-based calligraphy game application for teaching activities. We investigated the impact of virtual time, space, and technical availability on learners' understanding, imagination, and interactivity in VR education, and then we evaluated the positive impact via learner feedback. Research tools that we utilized consist of comprehension, imagination, and how feedback motivation scales with effective learning; we have also used Chinese calligraphy performance tests. The SPSS statistical analysis software was used for related statistical processing, and $\alpha$ was set to 0.05 . The results of this study indicated that Chinese calligraphy studies in VR time and space affect students' understanding and imagination but not their operational abilities. According to our research, a fundamental difference between traditional and modern teaching methods is a shift toward the use of VR (and the internet) in education. Therefore, the focus of this study is on understanding the impact on practical skills during distance learning and investing the impacts in order to form an effective approach to the use of VR in education.

Keywords: VR time and space, artificial intelligence, education strategy, distance education, Chinese calligraphy

\section{INTRODUCTION}

With the development of digital media technology, educational contexts continue to push the boundaries of what "can" be done: what can be virtualized, monitored in real time, and simulated (Hu et al., 2021). The space for education and technical means of communication, and these interactions in operational skills education have been redefined. Given the influence of the current COVID-19 pandemic in particular, there is now an even greater demand for online distance education, whereby students and teachers can conduct educational learning without having to leave their homes. However, the limitations of online education have been a subject of criticism as practical courses cannot be taught in the usual way, and with distance learning, students may have to rely more on their imagination in certain aspects of the process. They cannot obtain in-person guidance from 
teachers, and teachers cannot obtain real-time feedback from students. The quality of knowledge transferred may also be limited by camera angles, screen size, and clarity. The conveying of information will be affected by abstract features of language and by feedback factors (which may not be timely), impinging on learners' ability to obtain key knowledge and grasp key concepts. This therefore highlights the importance of VR education, which can help teachers and students to overcome time and space restrictions, and conduct remote "face-to-face" communication; teachers can borrow the artificial intelligencebased generative adversarial network (GAN) technology to translate semantics for real-time dynamic images, practical courses can be "hands-on," and practical exercises can be conducted to obtain teacher guidance and feedback (Huang G et al., 2019; Huang Y. C et al., 2019).

Virtual reality (VR) technology consists of a fusion of multichannel forms of information, with the ability to create interactive, three-dimensional dynamic scenes and behavioral simulations, and it enables users to enjoy immersive experiences and benefit from other advantages, such as engaging at a higher cognitive level, experiencing the richness of a highly realistic simulation, and experiencing a diverse range of sensory stimuli ( $\mathrm{He}$ et al., 2019). VR can simulate a real panoramic experimental environment and dynamic simulation of experimental teaching methods and conditions, and it can also facilitate behavior-based interactions, thus having great potential for enhancing learners' cognitive and practical skills (Burdea et al., 2003).

Artificial intelligence (AI) technology has gradually matured in terms of image translation and dynamic image generation. It can also show important changes in voice visualization, which is self-evident for the role of education. 6DOF free-angle video collection technology can record dynamic 3-D stereo data in real time; as a result, it has great potential in operational skills training. Moreover, the lightweight, low cost, and versatility of motion-capture technology have extended the limits of people's participation in the virtual world and have made it impressively realistic. Cloud computing and the popularization of 5G technology have enabled distance education to become more real time, and with the application of VR technology, realistic distance learning has become more and more of a reality.

Therefore, when the combination of VR technology, artificial intelligence, and other related technologies is compared with the traditional education method, it presents the unique characteristics of non-face-to-face physical space, non-linear time, 360-degree real-time interaction, and artificial intelligence-based personalized teaching, replacing traditional in-person teaching and focusing on teaching and learning. Typically, teachers pass on knowledge via language and the written word (Kyrlitsias et al., 2020). During the listening process, students process information through their auditory organs, developing their own understanding of what they have been taught based on their very own interpretation of the knowledge they were taught. When they encounter problems that they do not understand, students can engage in language interaction, communicating with one another until a better level of understanding is achieved, and completing the teaching and learning process at the same time and in the same space as the teacher. However, because of the subjective nature of language and writing, there is often a discrepancy between what students understand and the knowledge taught by teachers during the communication. Teachers are required to demonstrate key aspects of learning or to use visual aids to assist teaching so that students can understand and remember. This is especially the case with skill-based teaching, such as Chinese calligraphy. Students are generally required to demonstrate their proficiency and articulate their understanding face to face, and students need teachers' guidance and constructive feedback when practicing. In traditional education, text, images, and videos can help students enhance their understanding of knowledge, but for operational teaching, intuitive teaching assistance cannot be obtained through abstract symbols (text, images, and videos).

The purpose of this study is to use the effectiveness of VR to teach Chinese books and paintings, analyze if VR is able to enable distance education, and explore the impacts of VR practical teaching. The advent of the VR era will change education further. It can enable students to communicate with teachers "face to face" in teaching scenarios in remote and unusual situations, and it can help students overcome learning obstacles via the Internet. It is also possible to reproduce abstract knowledge in real time in virtual contexts without being subjected to physical constraints or screen display limitations. VR can help teachers and apprentices practice skills, with 360-degree interactive observations and learning, and it can simulate the teaching methods of real-world technology majors (Chen and Deng, 2015).

This study started with the three characteristics of space-time (derived from immersion, focusing on the teachers and students in different spaces teaching in the same virtual environment), imagination, and interactive VR (Chen et al., 2019a; Lee et al., 2020). We investigated the effect of VR technology and artificial intelligence technology on VR-based skills distance learning and the effectiveness of learning, using the "You, Calligrapher" VRbased painting application as an experimental tool, utilizing a combination of quantitative and qualitative methods. The results of the study were then used to consider the implications for other applications in VR education.

The theoretical model of this study contains three characteristics of VR: immersion (virtual time and space) (TS), imagination (IM), and interactivity (IN). Impact on the learning effect (LE) of distance practical teaching; and the direct impact of the technical availability (TA) factor on the learning effect (LE) of distance practical teaching; then the technical availability has improved understanding of students (SC),-as shown in Figure 1.

Time and space are the rules of the real world that differ from the virtual world. Therefore, the space-time factors of the virtual world will result in changes to human lifestyle and behavior, break through the constraints of time and space, and be more conducive to promoting the realism and enhancing the immersion of distance education (TS to LE). The teaching of the real world has undergone formal changes in the virtual world through language communication, supplemented by visualized images, text, and other symbolic forms (Setti and Csapo, 2021). The visual display of virtual spaces will not be restricted by 
physical screens. As a result, it is easier to spread information; realize the three-dimensional integration of information, symbolic imaging, and dynamic characteristics; and change the understanding of learners (IM to LE). Practical teaching in the real world relies more on physical operational teaching, emphasizing one-on-one or one-to-many same-physical space teaching. However, the virtual space can achieve long-range synchronized operation teaching without physical materialization so that learners can observe the operation process of the lecturer with multiple angles and perspectives without physical objects and conduct synchronous operation exercises to obtain real-time feedback from teachers' guidance (IN to LE).

Technical availability is the decisive factor for the popularization of virtual reality. The continuous interactive update of technologies such as artificial intelligence, VR/AR, big data, 5G, cloud service, and marginal computing has prompted virtual reality distance education to become more simulated. As a result, human-to-human connectivity in the virtual world is more and more real time, diverse, and convenient, creating a seamless connection between the virtual world and the real world, and achieving more efficient teaching practices than that in the real world (TA to LE). Artificial intelligence teaching can also simultaneously translate teaching knowledge, transform voice information into visualized information in an instant, and then obtain the learner's knowledge mastery data through big data, giving learners more modest learning information quantities and methods (TA to SC). Finally, judging the improvements of the learners' learning effect, there is a positive impact on the learning efficiency, and it might also have a negative impact on the learners' independent learning motivation; so this article will conduct research and exploration (SC to LE).

\section{LITERATURE REVIEW}

\subsection{The Status of VR Technology Applied to Practical Teaching}

Virtual activities can help students master practical skills and can promote the development of students' cognitive skills through simulations of key knowledge and processes relevant to certain fields in the real world, or they can be substituted for real environments to a certain extent (Liu and Wang, 2011) (Liou et al., 2018). With the combination of VR technology, VR equipment, and three-dimensional interactive virtual digital resources, we can provide students with an integrated virtual learning environment to help them improve their academic achievement and learning motivation (Bogusevschi et al., 2020). It taught junior high-school students the concept of the water cycle and precipitation formation by combining VR technology and VR laboratories to enhance their interest in physical learning. As VR technology becomes ever more sophisticated, with the characteristics of virtual reality immersion, interactivity, and promotion of students' powers of imagination, researchers will try to increase the effectiveness of students' learning, ensuring safety and maximizing interest levels through game-based learning. However, few scholars have been able to effectively monitor the actual effectiveness of students' learning in the case of current online teaching and students' learning outcomes cannot be fed back; the time and space of teaching and learning are not uniform, and the interactive effect of online education is not ideal (Chiang, 2021). Although online education can incorporate the most advanced technology in the professional field, it is not intuitive enough to reach the caliber required for it to be as effective as education in the real world, nor can it participate in activities or propose a solution to ensure students' complete satisfaction.

\subsection{The Impact of VR Technology on Learning Effectiveness}

The study of the impact of VR technology on learning effectiveness is divided into two categories. One particularly useful approach is that of Wang (2020), who has proposed a method for improving reading of educational publications in VR environment through dual construction of content systems and interactive situations. Gao Haibo (2019) believed that VR teaching applications can enable practitioners to break free from the narrow view of traditional teaching that only focuses on knowledge transfer and change passive learning into active exploration, thereby enhancing learners' immersive experience and participation in learning (He. et al., 2019). They assert that gaming-based learning and the use of VR in education can enhance learners' motivation. Experimental data confirm that game-based VR education can effectively enhance the learning experience and improve teaching quality (Liu et al., 2019). They argue that artificial intelligence, VR, and AR technology can achieve better personalized teaching, relying on Internet-based technology to change educational visualization from a flat world to one that is more three-dimensional and clearer. Sitterding (2019) added VR and artificial intelligence methods to the training of new nurses in American hospitals. In experiments comparing traditional training and VR training, it was found that VR training may be more effective than traditional teaching methods (Horváth et al., 2021, Hsiao et al., 2021).

On the other hand, it has been argued that the application of VR technology to education will bring a higher cognitive load and will not significantly promote the learning effect. For example, Parong et al. (2018) found that the cornerstone learning effect for learners using PowerPoint (PPT) was clearly better than that for learners using VR. The reason for this may be related to the immersive nature of the VR environment, which can produce greater external cognitive loads for learners, manifested in a low level of cognitive participation (reflected in learners' brainwave electrocardiograms) and poor migration test results. Makransky et al. (2017) used EEG equipment to track the brainwave status of desktop VR and headset-wearing VR learners, and found that learners were overloaded for nearly half of the time during the learning process, which may suggest that VR technology cannot improve the learning effect. Few scholars have conducted analysis of experimental data of the impact of VR on students' learning effectiveness from the 
perspective of the three characteristics of the VR technology described earlier, and then later used mature VR application software to analyze data relating to the experiences of users (Parong and Mayer, 2018; Paul and Jefferson, 2019).

\subsection{The Impact of Al Technology Applications on Student Learning}

An algorithm framework for AI GAN semantic translation generational learning technology was developed with the goal of facilitating unsupervised learning. This technology can be used for mutual conversion of texts and images in VR education, translation of voice images, image over-resolution, and dynamic image generation, and it can enable other machines to learn independently (Ninaus and Nebel, 2012). GAN is inspired by the two-person zero-sum game theory (Huang et al., 2012). Its unique adversarial training ideas can generate high-quality samples with more powerful learning and expression characteristics than traditional machine learning algorithms (Liang et al., 2013). The learning-generation process can help learners to select important information (images, text, sound, etc.) and organize this into new, continuous psychological representations in their working memory; finally, the new knowledge is integrated with existing knowledge and stored in long-term memory (Mayer, 2009). Few scholars have carried out relevant research on improving learners' understanding in a virtual environment from the dynamic translation of artificial intelligence semantics.

\subsection{Literature Summary}

In general, previous studies have actively explored and studied VR technology and AI technology in practical educational contexts from multiple angles, and improvements in students' learning and personalized education are particularly prominent. It has also been pointed out that current VR and AI technology are not yet mature, and there are many deficiencies.

Scholars often discuss the effectiveness of VR education from the perspectives of simulation safety of VR teaching and increased interest in games, from the three characteristics of VR: immersion (TS), imagination (IM), and interactivity (IN), as well as artificial intelligence. From a technical perspective, however, there are few scholars analyzing the effects of distance education and traditional online education, practical teaching in the VR environment, and the actual learning effect (LE) produced by the technical availability (TA) of artificial intelligence and VR technology on the understanding of students' acceptance of knowledge (SC).

In summary, this study will look at the development of virtual reality practical teaching and explore the impact VR technology and AI technology have on teaching and learning. Can remote face-to-face communication in VR time and space be achieved, and can teachers obtain student feedback in real time? When students have the opportunity to view teachers' demonstrations interactively in the VR environment, will it improve their learning effect on interactive operation exercises, and can dynamic knowledge translation be seen to occur?

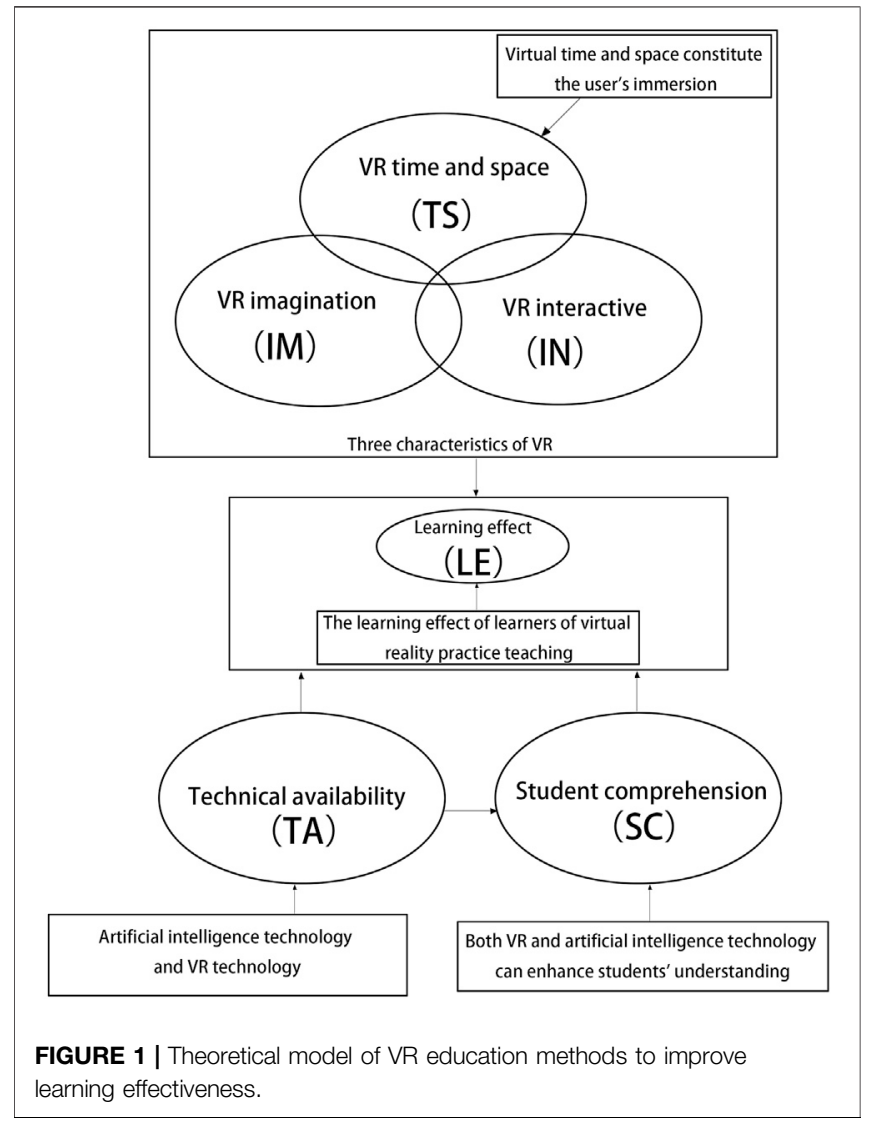

\section{RESEARCH METHODS}

\subsection{Research Assumptions and Framework}

VR technology has the three characteristics of immersion, imagination, and interaction. A VR-based immersive learning experience provides learners with an environment in which problems can be solved and knowledge can be acquired, and it can enable teachers and students in remote and foreign places to enjoy the benefits of face-to-face interaction at the same time (of particular relevance in the context of the COVID-19 pandemic). Therefore, in VR education, it will have a positive impact on the learning effect of learners. The artificial intelligence presentation of VR education will make a greater contribution to the performance of technical availability. Virtual reality technology has the three characteristics: imagination (IM), interactivity (IN), and immersion (virtual time and space) (TS). VR education provides learners with an environment to solve problems and acquire knowledge through immersive learning experience. Imagination and interactivity have a positive effect on learning effect (LE). The direct impact of the technical availability (TA) factor was generated by artificial intelligence and VR technology on the learning effect (LE) of remote practical teaching. Virtual real-life artificial intelligence will help the content of the lecturer to be translated from language to text, image translation, and image generation, and three-dimensional dynamic information generation transformation will have a positive impact on 


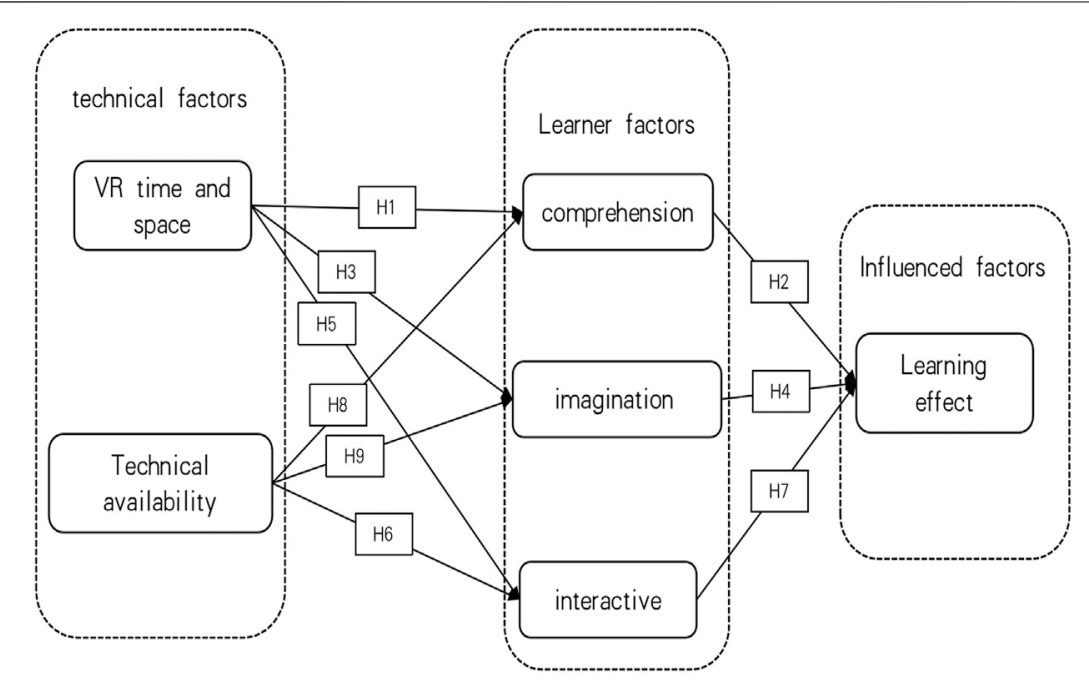

FIGURE 2 | Diagram of hypothetical model used in the study.

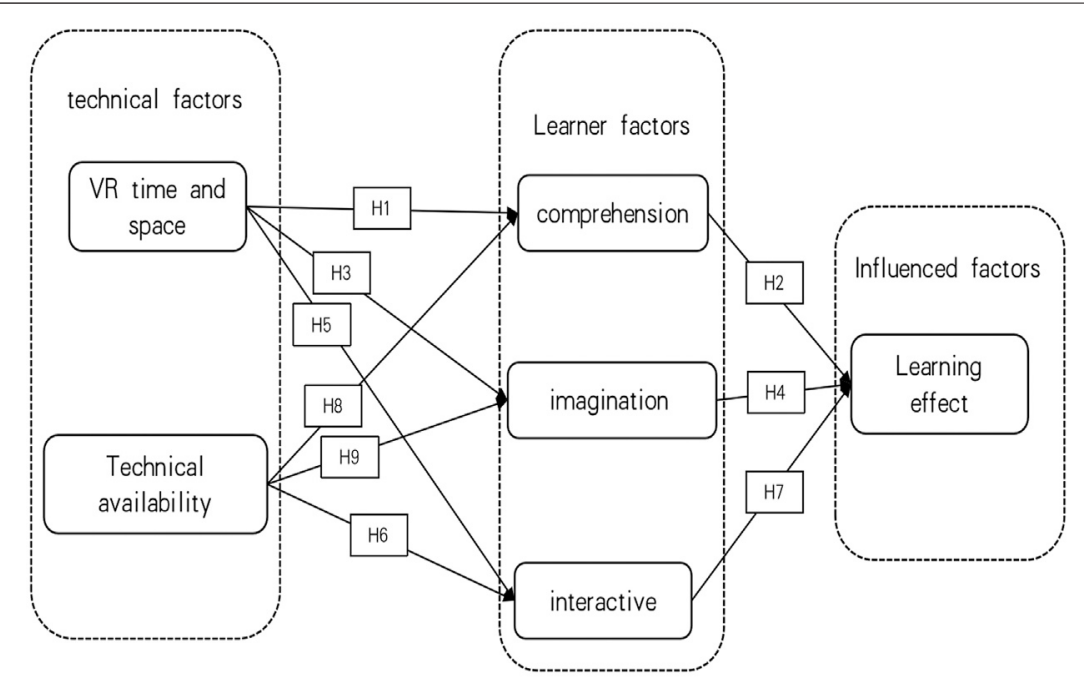

FIGURE 3 | "You, Calligrapher" VR application.

students' ability to understand (SC). Comprehension (SC) is the basic ability that affects the effectiveness of learning (LE), the basic ability of students to develop critical thinking and innovation skills, and an important ability that affects the long-term development of students (Chen et al., 2015).

It can be seen that space-time, technical availability, imagination, comprehension, and interactivity are crucial factors in students' learning. Therefore, this study adopted a theoretical model to explain the structural approach, and this enabled us to investigate the effectiveness of skill-based teaching using VR spatiotemporal characteristics, as shown in Figure 2.

In order to further explore the relationship between various influencing factors, nine possible relationships were hypothesized around these factors, and the nine assumptions in the theoretical model were as follows:

People can obtain more intuitive comprehension in VR time and space than in traditional imaging space (Feng 2006). Thus, hypothesis $1(\mathrm{H} 1)$ is suggested: VR time and space have a positive impact on students' understanding.

Learning without understanding is not real learning, and students' level of understanding will be reflected in learning outcomes. Therefore, evaluations of learning effects are essentially judgments about students' level of understanding (Chen et al., 2015). Hence, hypothesis 2 (H2) is proposed: Students' understanding has a positive impact on learning effectiveness. 
Teachers and students in VR time and space can access the same virtual teaching situation, with students receiving a valid and realistic (substitutive) learning experience ( $\mathrm{Wu}, 2017)$. A well-designed VR program will integrate the teaching content and strategies into the application context. It is necessary to consider VR space-time characteristics and link teachers' demonstration operations with learners' practice. VR space-time energy stimulates the human brain's ability to think imaginatively (Huang et al., 2010). Learners are more likely to learn abstract concepts in the VR space-time environment (He et al., 2019). As a result, hypothesis $3(\mathrm{H} 3)$ is formed: VR time and space have a positive impact on students' ability to use their imagination when learning.

Thinking power is the motor of intelligence. The power of thinking is weak. It directly affects the rationality and style of language, and language affects the intellectual development of learning and the geological formation of good ideas (Wei, 2017). Accordingly, hypothesis 4 (H4) is proposed: Students' imagination has a positive effect on learning.

McLuhan believes that the extension of human consciousness is constantly designed by electrons as a holistic world environment (Chen et al., 2015). A welldesigned VR application product integrates the teaching content and strategies into the application scene. It is necessary to consider the VR space-time characteristics and to link the demonstration operation of the lecturer with the practice of the learner. Subsequently, hypothesis 5 (H5) is proposed: VR time and space have a positive effect on interactivity.

VR technology can track learners' physical movements, activate time in the virtual world, and give learners a sensory experience that is so vivid and realistic as to seem physically real, akin to real-world activities but in a VR environment (He et al., 2019). Thus, hypothesis 6 (H6) is formed: Technology availability has a positive impact on VR interactivity.

Using VR technology, behavioral data relating to lecturers and learners via peripheral equipment (such as handles, helmets, and motion captures), interactive sensory means (such as audiovisual devices), and through forms of informational interaction between learners and VR education can be obtained, in order to promote learning. Interactive feedback helps learners construct meaningful knowledge (Huang et al., 2010). Hence, hypothesis 7 (H7) is suggested: The interactivity of VR has a positive impact on learning.

Virtual reality AI can help lecturers' language translation, image translation, image generation, and 3-D dynamic information generation, which will have a positive impact on students' ability to understand abstract information, enabling them to transform this into knowledge while enhancing interest levels and learning effects (Li et al., 2017). As a result, hypothesis 8 (H8) is proposed: Technology availability has a positive impact on learners' understanding.

With AI technology, voice or text can be converted into multiple languages, which can be displayed through images, 3D static and dynamic scenes, or objects. With VR technology, learners can use external equipment such as helmets, handles, headphones, microphones, and $\mathrm{Wi}-\mathrm{Fi}$ in different scenarios to interact, collaborate, and learn. VR technology can display things in multiple ways, helping learners to better understand virtual scenarios, boost their imagination, and reveal the essential characteristics of things (Li et al., 2017). Hence, hypothesis 9 (H9) is suggested: The availability of technology has a positive impact on learners' imagination.

\subsection{VR Application Design and Realization}

In this study, Oculus Quest2 VR equipment was used, a Chinese calligraphy and painting teaching application, and a virtual calligraphy painting application was developed using Unity $3 D$. "You, Calligrapher" is an educational application that integrates teaching and practice within a virtual environment,as shown in Figure 3. This application allows lecturers to demonstrate the teaching content in simulated ancient study rooms, emulating real-life teaching in the real world. Learners can experience an (simulated) in-person viewing process, like with traditional teaching (without being limited by position), observe the instructor's demonstration from any angle, and repeat the viewing at any point in time. Learners can also use helmets to access the virtual environment and experience contexts with traditional Chinese cultural characteristics, such as ancient calligraphy and Zen rooms. Learners use a handle to simulate an ink brush during the writing and painting process.

The "You, Calligrapher" software enables calligraphy learners to use distance learning methods and to practice in a virtual environment. There are two ways to watch video teaching materials, and users have a 360-degree view of the teaching content. Teaching demonstrations and activities are completed simultaneously, and the AI system scores learners' performance. The simulation process has three components: teaching, practice, and application. Learners complete the process of practicing writing during the game session.

The goal of the application is to train students to learn and improve their skills in calligraphy and Chinese painting techniques, with technical modeling and learning interaction. Learners' progress records are stored in real time in the database, and (via a manual intelligence algorithm evaluation) they receive instructional learning feedback, content frames, and feedback on the learning process.

The "You, Calligrapher" learning games include three components: teaching demonstrations, interactive practice, and breaking through the game level. Learners use voice and video teaching by "virtual teachers" in the game and do practice tasks, with a clear 360-degree view, enabling them to copy the teachers simultaneously. The second step involves learners using a game handle to simulate a brush, to obtain a realistic interactive writing experience and practice Chinese painting. They can also select relevant text or inscriptions from the database to copy. The third step is to complete the checkpoint task objectives (based on the present game) breaking through the game level. The AI algorithm evaluates feedback based on the learner's writing results and completes the process.

\subsection{Participants}

The study participants were educated to a higher level and were selected from students at the College of Art of Jinan 
University. This college runs a degree course on Chinese calligraphy and painting appreciation, and has an excellent reputation throughout the country. The study sample comprises 160 teachers and students of this subject (not just limited to teachers and students of calligraphy). The participants used the VR equipment at various times to experience the "You, Calligrapher" software (at least $30 \mathrm{~min}$ of painting study). An electronic questionnaire was drawn up and distributed to the research subjects, for them to report on their experience of using the VR equipment/software, using real-time communication tools such as micro credit and the QQ social application. In total, 160 questionnaires were distributed, and 152 valid questionnaires were recovered (a response rate of $95 \%$ ).

\subsection{Measurement Tools}

Learning effectiveness was assessed by the test questions, jointly prepared by the teacher and the researcher, including a "knowledge point understanding level" test and "technical ability" test. Participants took the tests as soon as they had finished using the application. In total, 152 effective test results were collected in this study. The "Education Questionnaire on the Effectiveness of Improving Practical Skills Teaching" included six dimensions: VR time and space, technical availability, interactivity, imagination, comprehension, and learning effects. Each dimension consisted of five questions (30 questions in total). The questionnaire was based on Huang et al.'s (2010) study. The original questionnaire used the Likert seven-point scale, which contains 16 topics. As this study was specifically focused on technical objectivity, a five-point Likert scale was used (1: "completely disagree," 2: "uncertain," 3: "not sure," 4: "agree," and 5: "fully agree"). Taking into account the particularity of distance learning practice technical courses, the content of three dimensions (VR time and space, technical availability, and comprehension) was replaced, -as shown in Table 1.

\subsection{Experimental Steps}

The first step entailed participants listening to an explanation and watching a demonstration (before the commencement of the experiment) to ensure that they understood the methods and precautions involved with the use of Oculus Quest2 and PICO NEO3, and that they understood the "You, Calligrapher" application. Participants could only proceed to the VR experience stage after the introduction by the research team. In the second step, the participants started the VR application, checked the position, adjusted the equipment to ensure that it was comfortable (e.g., the helmet and height of the virtual desktop), and started the experience.

With this application, the user needed to complete the teaching steps and freely write 16 Chinese characters. The game provided teaching feedback, and the same 16 Chinese characters could then be written again in three stages, with a completion time of 15-20 min. In the third step, the user was presented with the initial set of calligraphy results and the second set of results (after training and completing the VR experience), and then completed the questionnaire. In the fourth step, three professional teachers were asked to compare the calligraphy test results relating to the 16 Chinese characters, and a judgment was made as to the learning effect and the learning experience. The fifth step entailed data collection. IBM SPSS was used to describe participants' opinions of the VR application experience/ environment to perform descriptive statistical analysis and to analyze the impact of understanding, imagination, and interactivity on learning (through linear regression analysis). IBM SPSS was also used to verify the structural equations, and for factor analysis and path analysis.

\section{RESULTS ANALYSIS}

\subsection{Credit Effectiveness Analysis}

All participants completed the questionnaire online via the Internet, and 152 valid questionnaires were recovered. After revision, experts were invited to revise and conduct a lettereffectiveness analysis. In the letter-level analysis of the six variables, the Cronbach $\alpha$ coefficient value was found to be greater than 0.6 , thus indicating that the quality of the letter analysis was acceptable (Table 2). The Keyser-Meyer-Olkin (KMO) value was greater than 0.7 (0.710), indicating that the effect was good, and the common value was greater than 0.4 . The absolute value of the factor load coefficient of the variable corresponding to each factor was greater than 0.4 , and the vast majority of these were greater than 0.6 , indicating that the variable and the factor had a better correspondence (Table 3).

\subsection{Results Analysis}

\subsubsection{Descriptive Analysis of Variables Based on VR Time and Space in the Teaching Application}

The descriptive statistics on learners' attitudes toward the teaching application in terms of VR time and space were given in relation to six dimensions: VR time and space, technical visibility, imagination, understanding, interactivity, and the learning effect. The statistical results are listed in Table 4 Learners' overall attitude toward the VR environment was high (mean $=4.08)$. From the perspective of the cognitive level of each dimension, from high to low, the order was found to be as follows: understanding, technical visibility, learning effect, VR time and space, interaction, and imagination.

The average score for understanding was the highest (in the VR environment) and had a significant effect on understanding and skill improvement. The questionnaire item "You think VR education can help teachers and students to communicate face to face without space restrictions," in relation to the VR time and space variables, was divided into an average of 4.6 points (total score $=5$ points). The questionnaire item "You think VR6DOF teaching content is a more intuitive teaching experience than video format teaching" also scored 4.2 points (total possible score $=5$ points). Testers used this function repeatedly during the learning experience. The function enabling learners to closely watch the teacher's demonstration may fulfill an 
TABLE 1 | Participants' sociodemographic features [sample demographics ( $N=152)$ ].

\begin{tabular}{|c|c|c|c|}
\hline Background & Category & Frequency & Percentage \\
\hline \multirow[t]{2}{*}{ Gender } & Male & 77 & 50.7 \\
\hline & Female & 75 & 49.3 \\
\hline \multirow[t]{4}{*}{ Length of study time } & $0-1$ year & 53 & 34.8 \\
\hline & $1-3$ years & 28 & 18.4 \\
\hline & $3-5$ years & 41 & 26.9 \\
\hline & More than 5 years & 30 & 19.7 \\
\hline \multirow[t]{3}{*}{ Education } & College & 23 & 15.1 \\
\hline & Undergraduate & 87 & 57.3 \\
\hline & Postgraduate & 42 & 27.6 \\
\hline \multirow[t]{2}{*}{ Your identity in the field of calligraphy education } & Teacher & 19 & 12.5 \\
\hline & Student & 133 & 87.5 \\
\hline \multirow[t]{4}{*}{ The number of times you use VR equipment } & Not used & 26 & 17.1 \\
\hline & $1-2$ times & 54 & 35.5 \\
\hline & $3-5$ times & 43 & 28.3 \\
\hline & Often used & 29 & 19.1 \\
\hline
\end{tabular}

TABLE 2 | Cronbach credit analysis.

Variable

Number of items

VR time and space

Technical availability

Comprehension

Imagination

Interactive

Learning effect

2

2
2
3
3
3
2

Sample volume

152
152
152
152
152
152

Cronbach $\alpha$ coefficient

0.800
0.696
0.831
0.614
0.621
0.643

TABLE 3 | Results of effectiveness analysis.

Name

\begin{tabular}{lcc} 
& Factor $\mathbf{1}$ & Factor $\mathbf{2}$ \\
\hline A1 & & \\
A2 & 0.147 & 0.070 \\
B1 & 0.102 & 0.069 \\
B2 & 0.035 & 0.049 \\
C1 & -0.025 & 0.058 \\
C2 & 0.835 & -0.152 \\
C3 & 0.831 & 0.200 \\
D1 & 0.907 & -0.036 \\
D2 & 0.068 & 0.778 \\
D3 & -0.059 & 0.837 \\
E1 & -0.017 & 0.564 \\
E2 & -0.031 & 0.088 \\
E3 & 0.022 & -0.169 \\
F1 & 0.083 & -0.163 \\
F2 & -0.100 & 0.224 \\
KMO value & 0.031 & -0.093 \\
p value & 0.710 & \\
& 0.000 &
\end{tabular}

\section{Factor load coefficient}

$\begin{array}{cc}\text { Factor } 3 & \text { Factor } \mathbf{4} \\ -0.015 & 0.895 \\ 0.002 & 0.875 \\ -0.144 & 0.082 \\ 0.072 & 0.117 \\ 0.047 & -0.051 \\ -0.013 & 0.196 \\ 0.030 & 0.159 \\ -0.087 & 0.134 \\ -0.032 & -0.043 \\ -0.111 & 0.070 \\ 0.800 & -0.077 \\ 0.674 & -0.003 \\ 0.752 & 0.076 \\ 0.105 & -0.073 \\ -0.143 & 0.132 \\ & \\ & \end{array}$

Common degree (public factor difference)

0.831

0.830

0.661

0.597

0.729

0.778

0.851

0.695

0.749

0.401

0.660

0.519

0.655

0.672

0.705

TABLE 4 | Correspondence between variables and factors.

\begin{tabular}{|c|c|c|c|c|c|}
\hline $\begin{array}{l}\text { VR time } \\
\text { and space }\end{array}$ & $\begin{array}{l}\text { Technical } \\
\text { availability }\end{array}$ & Comprehension & Imagination & Interactive & Learning effect \\
\hline $\mathrm{A} 1, \mathrm{~A} 2$ & $\mathrm{~B} 1, \mathrm{~B} 1$ & $\mathrm{C} 1, \mathrm{C} 2, \mathrm{C} 3$ & D1, D2, D3 & E1, E2, E3 & $\mathrm{F} 1, \mathrm{~F} 2$ \\
\hline
\end{tabular}


TABLE 5 | Statistical table showing descriptions of learning effect variables.

\begin{tabular}{lccc}
\hline Name & Sample volume & Average & Standard deviation \\
\hline VR time and space & 152 & 4.049 & 0.709 \\
A1 & 152 & 4.066 & 0.769 \\
A2 & 152 & 4.033 & 0.784 \\
\hline Technical availability & 152 & 4.092 & 0.634 \\
B1 & 152 & 4.145 & 0.732 \\
B2 & 152 & 4.039 & 0.821 \\
\hline Comprehension & 152 & 4.226 & 0.649 \\
C1 & 152 & 4.349 & 0.783 \\
C2 & 152 & 4.125 & 0.684 \\
C3 & 152 & 4.204 & 0.783 \\
\hline Imagination & 152 & 4.015 & 0.562 \\
D1 & 152 & 3.974 & 0.736 \\
D2 & 152 & 4.099 & 0.761 \\
D3 & 152 & 3.974 & 0.745 \\
\hline Interactive & 152 & 4.046 & 0.564 \\
E1 & 152 & 4.105 & 0.738 \\
E2 & 152 & 4.000 & 0.709 \\
E3 & 152 & 4.033 & 0.792 \\
\hline Learning effect & & 4.056 & 0.759 \\
F1 & 152 & & \\
F2 & & 4.033 & \\
\hline & 152 & & \\
\hline & & & \\
\hline
\end{tabular}

aspect of teaching that regular online teaching cannot achieve, and the virtual live experience is even higher than the actual live demonstration experience. This discovery validates the findings of previous studies, that is, that the VR space-time environment can provide an immersive teaching and learning experience, which helps improve learning effectiveness, as shown in Table 5.

\subsubsection{Structural Equations for Factors Influencing Learning Motivation in the VR Environment} 4.2.2.1 Establishment and Evaluation of Structural Equation Models

IBM SPSS was used for modeling and test fitting, and to produce a structural equation model for the theoretical model of teaching effectiveness in relation to VR spatiotemporal characteristics. The model's proposed index was as follows: $\chi 2=101.673, \mathrm{df}=80$, IFI $=0.958, \mathrm{CFI}=0.956$, TLI $=0.942$, and $p=0.051>0.05$. The overall model adaptation met the standard, and the proposed fit was good. It can be seen that VR time and space interactivity, technical availability and comprehension, interactivity, and learning effect coefficients are negative, and the path coefficients between other variables were positive values, as shown in Table 6.

Through statistical inspection and analysis of the structural equations, the standard path coefficient and distinctive results were obtained, as shown in Table 7. The $p$ value of $\mathrm{H} 1$ and $\mathrm{H} 4$ reached a significant level of 0.01 , indicating that VR time and space have a positive and significant impact on learners' understanding, and imagination has a positive and significant impact on learning effects. The $p$ values of $\mathrm{H} 2, \mathrm{H} 6$, and $\mathrm{H} 9$ reached a significant level of 0.05 , indicating that learners' understanding has a positive and significant impact on the learning effect, technical availability has a positive and significant impact on interactivity, and technical availability has a positive impact on learners' imagination. The $p$ value of $\mathrm{H} 3$ reached a significant level of 0.1 , indicating that VR time and space have a positive and significant impact on learners' imagination. The $p$ values of $\mathrm{H} 5, \mathrm{H} 7$, and $\mathrm{H} 8$ did not reach a significant level, indicating that VR time and space do not have a positive and significant impact on interactivity. Interactivity has no positive and significant impact on learning effects, and technical availability has no positive and significant impact on understanding. Judging from the size of the standard path coefficient value, the variable effect of $\mathrm{H} 3$ was weak.

\subsubsection{Path Analysis Model of Factors Influencing Learning in the VR Environment}

The relationship model of factors influencing learning is shown in Figure 4 (based on the hypothesis test analysis of the model). This indicated that learners' understanding and imagination can significantly positively affect learning. VR time and space and technical availability have a positive impact on learners' understanding and imagination. It can be seen from the effect value between the paths in the figure that in the VR learning environment, the factor exerting the greatest impact on learning was imagination, and the direct effect value of this was found to be 0.274 . The second factor was that of comprehension, and the direct effect value of this was 0.073 . The effect value of both in terms of learning in the VR environment was 0.347 . The impact of VR time and space on understanding was greater than the impact of VR time and space on imagination. The effect value of VR time and space in terms of learners' understanding was 0.317 , and the effect value of VR time and space for learners' imagination was 0.065 . The effect value of technical availability in terms of interactive effects was 0.363 ,-as shown in Figure 5.

\section{DISCUSSION}

Our results indicated that in terms of VR-based educational games, VR time and space and technical availability are the factors that have the greatest effect on learning, and they have a direct impact on the learners' understanding, imagination, and interactivity. From the perspective of learning effects, learners' understanding and imagination have a direct effect, but interactivity does not significantly impact it.

The results indicated that overall, our expectations were met. VR space-time variables have a significant effect on learners' understanding and imagination, indicating that VR's immersive and trans-time characteristics have a positive impact on teachers and students. The technical availability of VR technology and artificial intelligence also have a positive impact on learners' imagination and the interactive experience, indicating that technology plays an important role in facilitating learners' perceptions of the VR environment in a multidimensional way. The $6 \mathrm{DOF}$ interactive application can enable learners to 
TABLE 6 | Model fitting indicators.

\begin{tabular}{|c|c|c|c|c|c|c|c|}
\hline Commonly used indicators & $\chi^{2}$ & df & IFI & CFI & TLI & IFI & $p$ \\
\hline Judgment criteria & - & - & $>0.9$ & $>0.9$ & $>0.9$ & $>0.9$ & $>0.05$ \\
\hline Value & 101.673 & 80 & 0.958 & 0.956 & 0.942 & 0.958 & 0.051 \\
\hline
\end{tabular}

TABLE 7 | Standardized regression coefficient and its distinctiveness.

\begin{tabular}{|c|c|c|c|c|c|}
\hline Hypothesis & Path description & $\begin{array}{c}\text { Standardized regression } \\
\text { coefficient }\end{array}$ & $\begin{array}{l}z \text { (CR } \\
\text { value) }\end{array}$ & $p$ value & $\begin{array}{c}\text { Hypothesis whether } \\
\text { it is } \\
\text { passed }\end{array}$ \\
\hline $\mathrm{H} 1$ & VR time and space $\rightarrow$ comprehension & 0.317 & 2.864 & 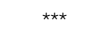 & Y \\
\hline $\mathrm{H} 2$ & Comprehension $\rightarrow$ learning effect & 0.073 & 0.907 & 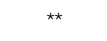 & Y \\
\hline $\mathrm{H} 3$ & VR time and space $\rightarrow$ imagination & 0.065 & 0.556 & * & Y \\
\hline $\mathrm{H} 4$ & Imagination $\rightarrow$ learning effect & 0.274 & 2.902 & $\star \star \star ~$ & Y \\
\hline H5 & VR time and space $\rightarrow$ interactive & -0.109 & -0.824 & 0.410 & $\mathrm{~N}$ \\
\hline H6 & Technical availability $\rightarrow$ interactive & 0.363 & 1.817 & $\star \star$ & Y \\
\hline $\mathrm{H} 7$ & Interactive $\rightarrow$ learning effect & -0.119 & -1.207 & 0.227 & $\mathrm{~N}$ \\
\hline H8 & Technical availability $\rightarrow$ comprehension & -0.097 & -0.767 & 0.443 & $\mathrm{~N}$ \\
\hline H9 & Technical availability $\rightarrow$ imagination & 0.264 & 1.610 & ** & $Y$ \\
\hline
\end{tabular}

Note: ${ }^{*} \mathrm{p}<0.10$, which was significant at $10 \% ;{ }^{* *} \mathrm{p}<0.05$, which was significant at $5 \%$; ${ }^{* *} \mathrm{p}<0.01$, which was significant at $1 \%$.

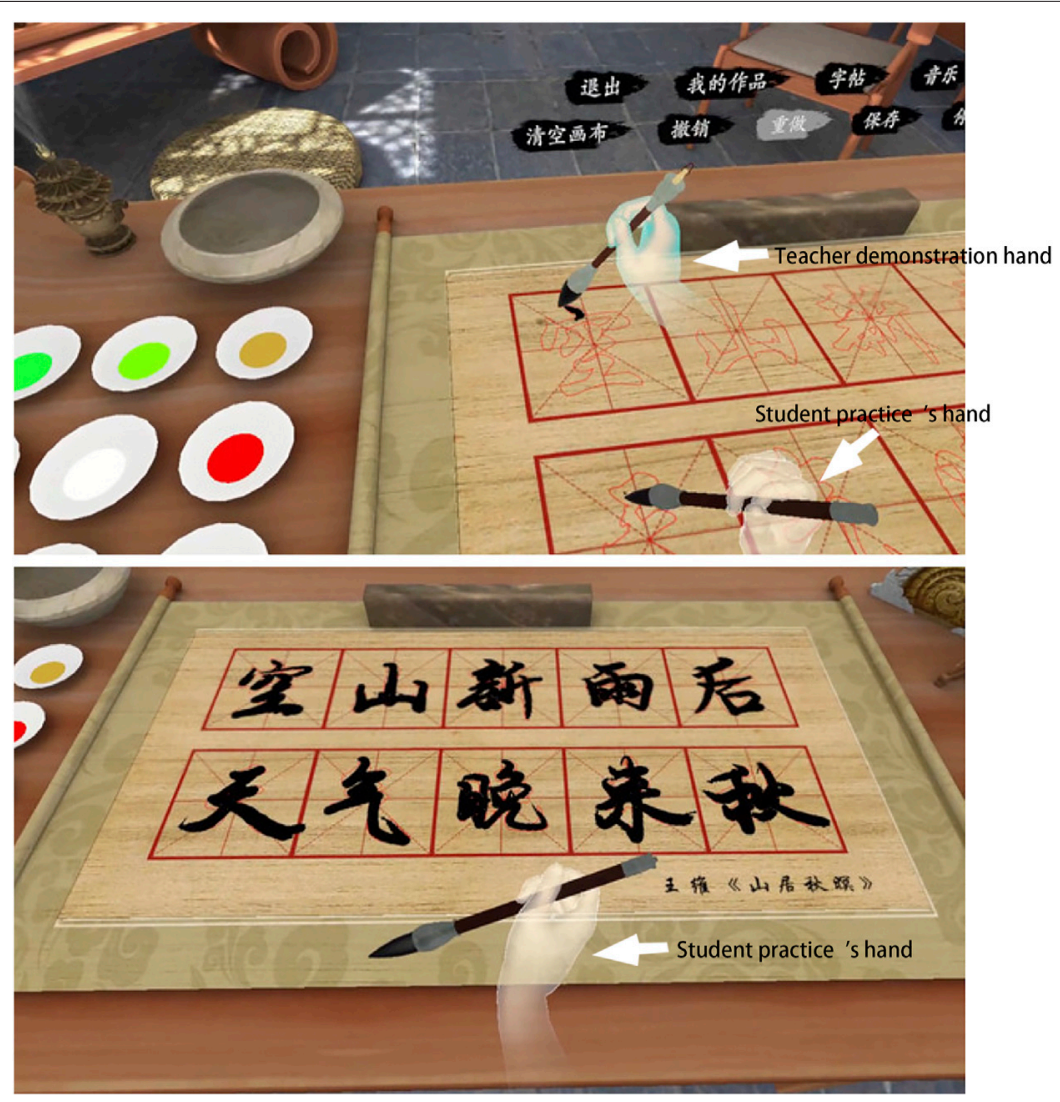

FIGURE 4 | "You, Calligrapher" operating interface. 


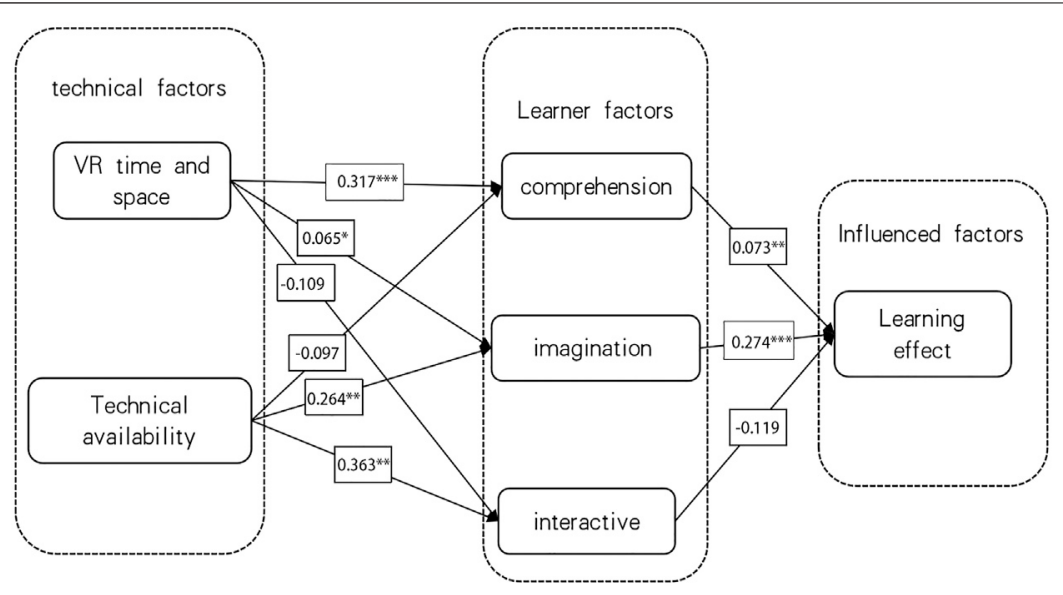

FIGURE 5 | Relationship model of VR time and space characteristics influencing skill-based learning.

engage with learning in a very lifelike way, as they would in the physical world, with VR creating a well-matched projection of real-time and space sensory feedback within a virtual world. Improvements in both learners' understanding and imagination have a positive impact on learning, indicating that in information processing and in-depth learning, cognitive understanding and imaginative thinking promote the effectiveness of learning. Dizziness and the controller affected the user experience to a certain extent; consequently, the learning effect was impacted negatively.

\subsection{Theoretical Implication}

Immersive VR technology creates a learning environment that simulates the physical world, allowing learners to obtain sensory immersion ( $\mathrm{Hu}$ et al., 2021). VR time and space blur the boundary between real-time and space and virtual time and space, creating a sense of presence that is not limited by such physical constraints, enabling teachers and students to communicate face to face and enhancing the possibility for teaching supervision and feedback. With the enhancement of the body's perception function, multimode characteristics can enhance the level of stimulation, providing lifelike learning contexts that amplify users' emotional response and sensory experience, making it easier for them to understand key information. Related EEG studies have further confirmed that in a VR environment, the human brain is more likely to present a neural pattern similar to that of the real thing (Petukhov et al., 2020). On a theoretical level, this provides strong evidence that VR's space-time nature creates a sense of learning "in situ" and improves learners' understanding. Such findings also indicate that the technical availability of VR and artificial intelligence has a positive effect on learners' imagination and knowledge acquisition.

However, it has also been found that the interactivity of VR technology can pose major problems, and its high-dimensional characteristics can have a negative impact on the learning process. For example, a VR environment has been known to cause higher cognitive loads and physiological discomfort for learners (such as dizziness and unrealistic controller interaction). Therefore, we should be cautious about VR education and be alert to the impact of redundant information with multidimensional perception, which interferes with learners' information acquisition.

\subsection{Practical Implication}

As of now, the world is still being affected by the COVID-19 pandemic, and social gatherings are severely restricted. Education has been significantly affected by lockdowns and restriction of inperson teaching, especially where practical skills are concerned. Although knowledge can be imparted via distance learning, it is almost impossible to know whether learners have actually acquired such knowledge. In the case of practical skills, students accessing online learning (e.g., in fields such as art, experimental disciplines, and vocational skills) must draw heavily on their imagination. Teachers can only use cameras to shoot the demonstration process, and learners watch teaching videos in order to learn how to carry out the practices in question for themselves.

Some believe that VR will revolutionize education. Teaching processes that can be completed by VR and AI technology for "teacher and apprentice" teaching (including those that require considerable teacher input, as with Chinese calligraphy) can be applied to distance learning using VR technology, and the addition of AI can effectively improve learners' understanding and powers of imagination. But at the same time, we must also realize that VR and AI still have a long way to go before popularizing education in general. The technical barriers associated with VR equipment (e.g., VR equipment's stunning, simulation of interactive handles, tactile simulation, and other technologies) are obstacles that practitioners need to overcome.

The author proposes the following as potential applications for improving the effectiveness of learning through the use of VR technology:

\subsection{Improve the Role of VR Education}

Given the particularity of distance education, different users clearly need to feel confident about the identity of the other 
party involved in the VR process. Traditional education has a clear identity authentication relationship in a fixed environment scenario, and it is easier for those involved to establish identity relationships with one another. The identity of the teaching and receiving parties is fixed. The relationship between the two is stable, with a guaranteed sense of trust and authority, and given these conditions, the teaching and learning process can progress and produce results.

\subsection{Improve Interaction Through Use of VR Education}

The function that Internet-based education cannot achieve for traditional skills teaching is the operability of students. Whether lesson materials are accessed via a computer or using mobile data, the process is limited by the user's input method, that is, a mouse, keyboard, or touch screen, and these modes of operation cannot achieve the interactive functionality of VR technology, with its ability to simulate reality. However, VR can break this deadlock, combining operational interaction with teaching. This technology not only makes it possible for students and teachers to communicate face to face, with teachers modeling key operations in real time, but it also means that students can actually practice the skills involved and obtain feedback on their performance and progress in real time.

\subsection{Improve Understanding of Teaching Content and Performance Using VR}

In the age of artificial intelligence, the conversion power of language has greatly increased. Real-time translation of language can be achieved through AI, and real-time translation (or conversion) of language to text and text to language, along with real-time translation of language to images, text to images, and even translation of images themselves, can be achieved. Fully intelligent real-time interpretation will be the basic feature of the AI age. In the VR space, the screen is no longer limited by factors such as size and cost. An image of a teacher, real-time translation of language, and text and images can be displayed in the virtual space, which will greatly enhance students' understanding. With the popularization of the $5 \mathrm{G}$ network (and with the help of cloud storage servers), lightweight VR equipment is on its way to becoming a feature of daily life, and it is likely to have a huge transformative effect on education.

\subsection{Improve the Design of VR Education and Learning Initiatives}

It can be difficult to know how to improve learning initiatives in any educational form, but VR in education is likely to become more prominent. Virtual environments make it impossible for students to stop listening and to disengage. This is very different from normal online programs, where there may be no supervision mechanism, making it possible for students with poor autonomy to lose interest and learn bad habits (especially in the case of younger students). This problem has become very prominent in the Internet age. During COVID-19 lockdowns, teachers have found it difficult to sustain students' attention between screens, and the systems used may not have a feedback mechanism. Although video conferencing can effectively alleviate this problem with network technology, it is still impossible to achieve the same effect as classroom teaching in the case of distance learning. Teacher supervision and face-to-face contact with students may be almost zero, and a classroom learning atmosphere is difficult to be established. Therefore, in the era of VR education, there is a need to solve this problem in order to achieve true distance education and provide an alternative form of face-to-face teaching.

\section{CONCLUSION}

Through our experimental test with the Chinese "You, Calligrapher" VR software, it was found that VR education has a positive effect on learners and teachers in distance education, and this technology can help teachers and students establish an effective "face-to-face" teaching environment and solve the difficulties associated with supervision and providing teacher feedback. Practical skills education in particular can greatly benefit from this approach, meeting the needs of both teachers and learners. The results show that VR time and space can significantly enhance the learning of practical skills. VR space-time is the most important difference between online teaching and traditional education. Technical availability is key to content presentation and, in combination with $\mathrm{AI}$, is a great way to improve the communicative efficiency of teachers and students. Interaction helps promote more intuitive teaching and learning, and synchronization of understanding and imagination is key to students' knowledge formation. These are some of the core elements of education and have been shown to have a positive impact on learning effects.

\subsection{Limitation and Future Work of Study}

The research on VR education in this subject is not deep enough, and there is a lack of more diverse experimental samples of educational content. The scope of the experiments is not wide enough, and further observations and experiments are needed to obtain richer data. In the future, we hope to obtain more samples of VR education applications and expand the experimental data population, such as the elderly and school-age children, to obtain a larger amount of data to test the accuracy of research conclusions.

\subsection{Academic Contribution}

Research into educational psychology training mainly focuses on educators and future developments. Existing research belongs to the fields of pedagogy and computer science. According to previous studies, research has focused on the linearization of skill-based education, with artificial 
intelligence and virtual reality technology as variable factors, trying to improve the traditional education model, and the purpose is to improve the efficiency of distance operational skill teaching. We used software to test a contemporary Chinese age-group and obtained relevant data for analysis, to clarify the effectiveness of the method, and to make relevant recommendations (to the government and industry) based on the research results.

\section{DATA AVAILABILITY STATEMENT}

The raw data supporting the conclusions of this article will be made available by the authors, without undue reservation.

\section{AUTHOR CONTRIBUTIONS}

PL designed the study, participated in all steps of the research process, and wrote the first draft. TJ made a substantial and

\section{REFERENCES}

Chen, M. X., and Deng, Z. (2015). The Transformation of Learning Evaluation in the Process of Educational Informatization-A Understanding-Based Perspective. Int. J. E-education Res. 36 (10), 12-19. doi:10.13811/j.cnki.eer. 2015.10.002

Chen, X., Chen, S., Ma, Y., Liu, B., Zhang, Y., and Huang, G. (2019a). An Adaptive Offloading Framework for Android Applications in Mobile Edge Computing. Sci. China Inf. Sci. 62, 82102. doi:10.1007/s11432-018-9749-8

Chen, X., Li, A., Zeng, X. e., Guo, W., and Huang, G. (2015). Runtime Model Based Approach to IoT Application Development. Front. Comput. Sci. 9, 540-553. doi:10. 1007/s11704-015-4362-0

Chiang, T. H. (2021). Investigating Effects of Interactive Virtual Reality Games and Gender on Immersion, Empathy and Behavior into Environmental Education. Front. Psychol. 12, 608407. doi:10.3389/fpsyg.2021.6084010.3389/fpsyg.2021. 608407

Feng, D. (2006). VR's Ontology Exploration. J. Hefei Ind. Univ. (Social Sci. Edition) (01), 167-170. doi:10.3969/j.issn.1008-3634.2006.01.039

He, J. H., Huang, X. L., Han, G. X., Liang, Y. S., and He, X. Q. (2019). Empirical Research on the Influence Factors of VR Educational Game Learning Motivation. Int. J. Electr. Educ. Res. 40 (08), 70-77. doi:10.13811/j.cnki.eer.2019.08.009

Horváth, I. (2021). An Analysis of Personalized Learning Opportunities in 3D VR. Front. Comput. Sci. 3, 673826. doi:10.3389/fcomp.2021.673826

Hsiao, S. C. (2021). Effects of the Application of Virtual Reality to Experiential Education on Self-Efficacy and Learning Motivation of Social Workers. Front. Psychol. 12, 770481. doi:10.3389/fpsyg.2021.770481

Hu, Y. L., Nie, J., Zhang, T. Q., and Wu, T. (2021). The Effectiveness of VR Technology Empowerment Experimental Teaching under the Field of Personal Cognitive Vision. Int. J. Mod. distance Educ. Res. 33 (05), 94-102. doi:10.3969/j. issn.1009-5195.2021.05.010

Huang G, G., Liu, X., Ma, Y., Lu, X., Zhang, Y., and Xiong, Y. (2019). Programming Situational Mobile Web Applications with Cloud-Mobile Convergence: an Internetware-Oriented Approach. IEEE Trans. Serv. Comput. 12, 6-19. doi:10.1109/TSC.2016.2587260

Huang, G., Chen, X., Zhang, Y., and Zhang, X. (2012). Towards Architecture-Based Management of Platforms in the Cloud. Front. Comput. Sci. 6 (4), 388-397. doi:10. 1007/s11704-012-2100-4

Huang, G., Xu, M., Lin, F. X., Liu, Y., Ma, Y., Pushp, S., et al. (2017). Shuffledog: Characterizing and Adapting User-Perceived Latency of Android Apps. IEEE Trans. Mobile Comput. 16, 2913-2926. doi:10.1109/TMC.2017.2651823 direct intellectual contribution to this work, reviewed the literature, revised the manuscript, and participated in the interpretation of the results. ZF has contributed to data collection, statistical analysis, and writing, and is responsible for communication. All authors approved the manuscript and agreed to be responsible for all aspects of the work.

\section{FUNDING}

This research was supported by the new engineering construction project of the Chinese Ministry of Education's collaborative education project (VR virtual simulation collaborative education platform construction) (2018), the "13th Five-Year Plan" project of the development of philosophy and social sciences of Guangzhou City, Research on International Economic Cooperation and Competition in the Bay Area" (2019GZGJ33).

Huang, H.-M., Rauch, U., and Liaw, S.-S. (2010). Investigating Learners' Attitudes toward Virtual Reality Learning Environments: Based on a Constructivist Approach. Comput. Educ. 55 (3), 1171-1182. doi:10.1016/j.compedu.2010.05.014

Huang, Y. C, Y.-C., Backman, S. J., Backman, K. F., McGuire, F. A., and Moore, D. (2019). An Investigation of Motivation and Experience in Virtual Learning Environments: a Self-Determination Theory. Educ. Inf. Technol. 24 (1), 591-611. doi:10.1007/s10639-018-9784-5

Kyrlitsias, C., Christofi, M., Michael-Grigoriou, D., Banakou, D., and Ioannou, A. (2020). A Virtual Tour of a Hardly Accessible Archaeological Site: The Effect of Immersive Virtual Reality on User Experience, Learning and Attitude Change. Front. Comput. Sci. 2, 23. doi:10.3389/fcomp.2020.00023

Lee, C. C., Hsiao, K. L., and Chen, C. C. (2020). Exploring the Benefit and Sacrifice Factors of Virtual Reality Gameplay. Front. Psychol. 11, 251. doi:10.3389/fpsyg. 2020.00251

Li, X. P., Chen, J. Z., Zhao, F. N., Zhang, L., and Zhang, G. G. (2017). AR/VR Research on the Design of Learning Situations. J. Mod. Educ. Technol. 27 (8), 12-17. doi:10.3969/j.issn.1009-8097.2017.08.002

Liang, C., Hsu, Y., Chang, C.-C., and Lin, L.-J. 2013). In Search of an index of Imagination for Virtual Experience Designers. Int. J. Technol. Des. Educ., 23(4): 1037-1046. doi:10.1007/s10798-012-9224-6

Liu, X. B., and Wang, G. X. (2011). Desktop Virtual Experiments Promote the Verification and Analysis of Student Operation Skills' Migration. J. Distance Education China (11), 4296-4346. doi:10.3969/j.issn.1009458X.2011.11.009

Liu, X. X., Zhu, N., and Wang, L. F. (2019). Become "Stereotyped"-talk about How Artificial Intelligence, VR and AR Will Change the Future Development of Education. J. Occup. (07), 38-39. doi:10.3969/j.issn. 1009-9573.2019.07.016

Makransky, G., Terkildsen, T. S., and Mayer, R. E. (2019). Adding Immersive Virtual Reality to a Science Lab Simulation Causes More Presence but Less Learning. Learn. Instruction 60, 225-236. doi:10.1016/j.learninstruc.2017.12.007

Ninaus, M., and Nebel, S. (2021). A Systematic Literature Review of Analytics for Adaptivity within Educational Video Games. Front. Educ. 5, 611072. doi:10. 3389/feduc.2020.611072

Parong, J., and Mayer, R. E. (2018). , Cognitive and affective processes for learning, science in immersive virtual reality. J. Educ. Psychol. 110 (6), 785-797. doi:10.1111/ JCAL. 12482

Paul, J., and Jefferson, F. (2019). A Comparative Analysis of Student Performance in an Online vs. Face-To-Face Environmental Science Course from 2009 to 2016. Front. Comput. Sci. 1, 7. doi:10.3389/fcomp.2019.00007 
Petukhov, I. V., Glazyrin, A. E., Gorokhov, A. V., Steshina, L. A., and Tanryverdiev, I. O. (2020). Being Present in a Real or Virtual World: A EEG Study. Int. J. Med. Inform. 136, 103977. doi:10.1016/j.ijmedinf. 2019.103977

Setti, T., and Csapo, A. B. (2021). A Canonical Set of Operations for Editing Dashboard Layouts in Virtual Reality. Front. Comput. Sci. 3, 659600. doi:10. 3389/fcomp.2021.659600

Sitterding, M. C., Raab, D. L., Saupe, J. L., and Israel, K. J. (2019). Using Artificial Intelligence and Gaming to Improve New Nurse Transition. Nurse Leader 17 (2), 125-130. doi:10.1016/j.mnl.2018.12.013

Wang, M. (2020). The Optimization Path of VR Educational Publications-The Dual Construction of "content + Situation. J. View Publishing (16), 44-46. doi:10.16491/j.cnki.cn45-1216/g2.2020.16.011

Conflict of Interest: Author ZF was employed by the company Guangzhou Nidu Information Technology Co., Ltd.
The remaining authors declare that the research was conducted in the absence of any commercial or financial relationships that could be construed as a potential conflict of interest.

Publisher's Note: All claims expressed in this article are solely those of the authors and do not necessarily represent those of their affiliated organizations, or those of the publisher, the editors, and the reviewers. Any product that may be evaluated in this article, or claim that may be made by its manufacturer, is not guaranteed or endorsed by the publisher.

Copyright $\odot 2022$ Li, Fang and Jiang. This is an open-access article distributed under the terms of the Creative Commons Attribution License (CC BY). The use, distribution or reproduction in other forums is permitted, provided the original author(s) and the copyright owner(s) are credited and that the original publication in this journal is cited, in accordance with accepted academic practice. No use, distribution or reproduction is permitted which does not comply with these terms. 